\title{
Compliance with antibiotic prophylaxis in urinary tract infection
}

\author{
A R Smyth, B A Judd
}

\begin{abstract}
Compliance with antibiotic prophylaxis after urinary tract infection was assessed in 32 children, using a parent questionnaire, and a urine test for antibacterial substances. In 31 $(97 \%)$ cases, parents reported giving the antibiotics every day but only $22(69 \%)$ of urine tests were positive. Failure to understand the reasons for prophylaxis and non-compliance were significantly associated.
\end{abstract}

(Arch Dis Child 1993;68:235-6)

A previous study has shown poor parental compliance in administering prophylactic antibiotics to children with a recurrent urinary tract infection (UTI), and an increased incidence of UTI as a result. ${ }^{1}$ Where vesicoureteric reflux has been demonstrated by micturating cystogram, antibiotic prophylaxis is an established treatment and may prevent renal scarring. ${ }^{2}$ The aim of this study was to estimate what proportion of children, receiving prophylactic antibiotics, complied with their treatment and to establish the reasons for non-compliance.

\section{Patients and methods}

Over four months, 32 patients were enrolled in the study at a median age of 3.3 years (range 4 months-12 years). Twenty four (75\%) patients were girls. Indications for prophylaxis were as follows: vesicoureteric reflux in 26 $(82 \%)$, obstructive lesions in three $(9 \%)$, and recurrent UTI in three (9\%). Children taking prophylactic antibiotics for less than four weeks were excluded. Median duration of treatment was 10 months (range 1-52 months).

The parent accompanying the child completed a closed questionnaire to establish how often they gave their child the antibiotics, whether they understood the reasons for prophylaxis, and whether the children were managed appropriately by their general practitioner (GP).

A urine specimen was obtained from each child and routine microscopy and culture performed. In addition each specimen was tested for antibacterial activity by means of a bioassay. The test organism used was a fully sensitive strain of Escherichia coli (NCTC 10418).

Total daily doses and dose intervals for the three antibiotics used were as follows: trimethoprim $2 \mathrm{mg} / \mathrm{kg}$ at night, nalidixic acid $6 \mathrm{mg} / \mathrm{kg}$ twice daily, and nitrofurantoin $1 \mathrm{mg} / \mathrm{kg}$ at night. Pharmacokinetic studies of trimethoprim and nalidixic acid indicate that concentrations exceeding the minimum inhibitory concentration, for the test organism, are present in the urine for at least 16 hours after the dose is administered. $^{3-5}$ Hence antibacterial activity should be detectable by the bioassay where the antibiotic has been correctly administered. However the pharmacokinetics of nitrofurantoin suggest that urinary concentrations would be less than the minimum inhibitory concentration for the test organism 12 hours after the dose was administered in children under 2 years. ${ }^{6}$ Hence children under 2, taking nitrofurantoin, were ineligible for the study and this resulted in one child being excluded.

The following factors were examined for an association with non-compliance: questionnaire responses, non-attendance at previous clinic appointments, and duration of prophylaxis.

Statistical analysis was by means of the $\chi^{2}$ test (using Yates's correction) and the MannWitney U test.

\section{Results}

Questionnaires and urine samples were obtained in 32 cases. Questionnaire responses are summarised in table 1 . In response to question 1 only one parent admitted stopping the antibiotic and he had been told that prophylaxis would be stopped on the next clinic visit. Antibacterial substances were detected in the urine in 22 $(69 \%)$ cases and were absent in $10(31 \%)$. Four (13\%) patients had one breakthrough infection each, which was due to a resistant organism in three cases. The fourth was non-compliant.

Question 2 assessed parents' understanding of prophylaxis. Of the 11 parents with a poor understanding, four were compliant and seven non-compliant. A poor understanding was significantly associated with non-compliance

Table 1 Results of parent questionnaire (\% in parentheses)

\begin{tabular}{l}
\hline 1. How many days per week do you give your child the antibiotics? \\
(Indicate $0-7$ days) \\
Every day \\
Never \\
$1 / 32(32(3)$
\end{tabular}

2. What do you think would happen if your child stopped taking the antibiotics?

a. Nothing

$10 / 32(31)$

c. Risk of kidney problems 21/32(66)

3. Who first explained the reason for your child taking antibiotics?

a. No explanation given reason for your child taking antibioits

b. Hospital doctor $30 / 32(94)$

c. Your GP

$2 / 32(6)$

4. Have you ever experienced difficulty getting repeat prescriptions for your GP?

a. No

$30 / 32(94)$

b. Yes

2/32(6)

5. When your child has an unexplained temperature does your GP test a specimen of urine?

a. Always

b. Sometimes

c. Never

d. No unexplained temperatures 
Table 2 Factors not associated with compliance (\% in parentheses)

\begin{tabular}{lcc}
\hline & $\begin{array}{l}\text { Compliant } \\
\text { group }\end{array}$ & $\begin{array}{l}\text { Non-compliant } \\
\text { group }\end{array}$ \\
\hline $\begin{array}{l}\text { Urine not tested } \\
\text { Repeat prescriptions }\end{array}$ & $8 / 22(36)$ & $5 / 10(50)$ \\
$\begin{array}{l}\text { not supplied } \\
\begin{array}{l}\text { Non-attendance at clinic } \\
\quad>2 \text { appointments) }\end{array}\end{array}$ & $2 / 22(9)$ & $0 / 10$ \\
$\begin{array}{l}\text { Median duration of } \\
\text { prophylaxis (months) } \\
\text { Range }\end{array}$ & $1 / 22(5)$ & $1 / 10(10)$ \\
\hline
\end{tabular}

$\left(\chi^{2}=6.05, p=0.014\right)$. The relative risk of noncompliance in this group was 2.4 (95\% confidence interval 1.07 to $5 \cdot 6$ ).

No association was found between the following factors and non-compliance: failure of the GP to test the urine and supply repeat prescriptions, non-attendance at previous clinic appointments, and duration of prophylaxis (table 2).

\section{Discussion}

In a previous study only $32 \%$ of children complied fully with medication, ${ }^{1}$ this contrasts with $69 \%$ who were compliant in our study, as indicated by the presence of antibacterial substances in the urine. Understandably, most parents were reluctant to report when their child was not taking their antibiotics.

Although all the parents recalled receiving an explanation of the reasons for prophylaxis, 11 had not fully understood this explanation. This lack of understanding was the only factor significantly associated with non-compliance.
Of the three children taking prophylaxis for recurrent UTI alone, all three parents were 'unsure' what would happen if they stopped giving their children the antibiotics and none complied. This suggests that compliance will be difficult to achieve for this indication unless both doctor and parent perceive it to be important.

Of those parents who attended their GP when their child had a temperature, $46 \%$ said their GPs never tested the urine. Breakthrough infecttion was common in our study (13\%) which suggests that urine testing should be routine when these patients attend with unexplained fever.

A clear explanation of the reasons for prophylaxis should be given at the outset of treatment and this should be re-enforced at each clinic visit. If necessary this should be accompanied by a written information sheet.

We are grateful to Mr G Williams for laboratory assistance.

1 Daschner F, Marget $W$. Treatment of recurrent urinary tract infection in children. 2. Compliance of parents and children with antibiotic therapy regimen. Acta Paediatr Scand 1975; with antibion-8.

2 Birmingham Reflux Study Group. Prospective trial of operative versus non-operative treatment of severe vesioperative versus non-operative treatment of severe vesi-
coureteric reflux in children: five years observation. $B M \mathcal{F}$ coureteric reflux in

3 Kucers A, Bennett NM, Kemp RJ. The use of antibiotics. A comprehensive review with clinical emphasis. 4th Ed. London: Heinemann, 1987:1131, 1252, 1278.

4 Rylance GW, George RH, Healing DE, Roberts DGV. Single dose pharmacokinetics of trimethoprim. Arch Dis Child 1985;60:29-33.

5 Bruhl P, Grundlach G, Winties K, Eichner W, Bastian HP. New studies of the pharmacokinetics of nalidixic acid. 1. Serum and urine levels in normal renal function. Arzneimittelforschung 1973;23:1311-3.

6 Wierzba K, Wankowicz B, Rogoyski A, et al. Experimental and clinical pharmacokinetics of nitrofurantoin in the early period of life. Padiatr Padol 1982;17:293-9. 